\title{
Opinion of Nigerian pharmacists on enlistment of physiotherapists as supplementary prescribers of relevant medications
}

\author{
Onigbinde Ayodele Teslim*, Ojo Mojisola Ayodele \\ Department of Medical Rehabilitation, College of Health Sciences, Obafemi Awolowo University, Ile-Ife, Osun State, Nigeria \\ Email address: \\ ayotesonigbinde@yahoo.co.uk (A. T. Onigbinde)
}

\section{To cite this article:}

Onigbinde Ayodele Teslim, Ojo Mojisola Ayodele. Opinion of Nigerian Pharmacists on Enlistment of Physiotherapists as Supplementary Prescribers of Relevant Medications. American Journal of Health Research. Special Issue: Supplementary Prescribing in Nigeria: A Needy Concept to Promote Clinical Physiotherapy Practice. Vol. 2, No. 5-1, 2014, pp. 29-33. doi: 10.11648/j.ajhr.s.2014020501.16

\begin{abstract}
There is increasing evidence that combining pharmacotherapy and physiotherapy is an effective tool towards effective management different pathologies. Physiotherapists in some countries have had prescription rights for more than a decade but this appears not to be the trend in Nigeria. In these countries, pharmacists played key roles in the change of policy which allowed allied health professionals to prescribe drugs. The primary aim of this study was to determine the opinion of pharmacists on the enlistment and legislation of physiotherapists as supplementary prescribers. A self administered questionnaire was used to obtain information from 110 pharmacists. Purposive sampling technique was used to select the hospitals and institutions. A descriptive statistics of frequency, percentages, standard deviation and Chi-square test were used to analyze the data. This study found that 70 respondents (70\%) supported the enlistment of Physiotherapists as Supplementary Prescribers in Nigeria. The result of the Chi-square test showed that the number of respondents who supported the formulation of policy to allow physiotherapists to prescribe was significantly higher than the number of respondents who opposed it $\left(\mathrm{X}^{2}=\right.$ $16.00 ; \mathrm{P}<0.001)$. Also, 60 respondents $(63.8 \%)$ are aware that physiotherapists are supplementary prescribers in some foreign countries. Also, 79 respondents (71.8\%) opined that physiotherapists should be allowed to prescribe NSAIDs while 73 (66.4\%) respondents opined physiotherapists should be allowed to prescribe analgesics. Most Pharmacists (71.9\%) are unaware that cardiopulmonary physiotherapists can prescribe inhaler for patients requiring the use in some foreign countries. This study concluded that most pharmacists are of the opinion that Physiotherapists should be enlisted as supplementary prescribers and that a policy should be formulated to guide prescription by them.
\end{abstract}

Keywords: Pharmacists, Physiotherapists, Supplementary Prescription, Drugs

\section{Introduction}

Physiotherapy is a health care profession concerned with human function and maximizing potentials using physical approaches to promote, maintain and restore physical, psychological and social well-being, taking accounts of variations in health status [1]. Physiotherapeutc care of patient can be facilitated by the timely administration of medicine and the ability to administer that medicine be given to the physiotherapy profession. This would maximize effective and timely use of resources [2]. Most physiotherapists are involved in Home-based Rehabilitation and they appear to spend longer period and sessions with patients [3]. Thus, most patients expect physiotherapists to give advice or prescribe medications.
Physiotherapy profession recognizes the benefits of extending prescribing rights in terms of benefits to patients, enhancing a physiotherapeutic intervention by the timely use of medication, improving long term care (like in asthma and anticoagulation), reducing patient anxiety, reducing the wait for medication, providing a cost-effective service to patients by reducing the number of visits to medical practitioners [2].

Australian community physiotherapists mostly operate as primary contact practitioners with an estimated $90 \%$ of their contacts related to musculoskeletal system [4]. Hence, concerns have been formally expressed regarding physiotherapists' role in drug administration since 1992 especially in prescription of analgesics and non steroidal anti- 
inflammatory drugs (NSAIDs [5]. Supplementary prescribing is an innovative policy development in the UK healthcare system in terms of healthcare professionals and service users [6]. Physiotherapists' ability to prescribe certain medication would be a major advantage in a country like Nigeria where it can take longer time to access a GP for a non-urgent medical issue, hence, it is pertinent to introduce SP innovations. There is a greater demand being placed on existing health care professionals coupled with increased cost-cutting measures in health care resulting in greater workload demands on clinical staff and managers [7].

Currently in the UK, physiotherapists can only prescribe medication when working with the written authority of a doctor and under this, physiotherapists would be able to prescribe a range of medication for respiratory diseases such as asthma, neurological conditions such as the effects of a stroke, and for pain relief. The advantage is that the new rights will relieve a currently unnecessary burden on doctors who are simply asked to write a prescription for medication recommended by the physiotherapist [8]. The Medicines Act of 1968 was reviewed in UK to develop a framework to determine situations in which health professionals could undertake new roles in prescribing medicines. The Chartered Society of Physiotherapists (CSP) responded to this review and argued that physiotherapists should be given opportunity to prescribe and administer drugs in order to improve patient's care and that it will maximize effective use of resources. UK Crown Report recommended that specialist physiotherapists be extended prescribing rights [9].

Supplementary prescribers are those responsible for continuing patients' health care after an initial assessment by an independent prescriber. They work with the independent prescriber to fulfil a clinical management plan between the prescriber and the patient $[10,11,12]$. Other supplementary prescribers are; nurses, pharmacists, podiatrists, diagnostic and therapeutic radiographers; and optometrists. Physiotherapists are involved in administering and supplying medications by two methods; "The Patient Specific Direction and The Patient Group Direction" However, there has been recommendations for change and improvement which included the extension of prescribing rights to specialist physiotherapists and such changes would require primary legislation [11]. National Health Services (NHS) employers are also making plans to empower appropriately qualified nurses, midwives and therapists to undertake a wider range of clinical tasks including the right to make and receive referrals, admit and discharge patients, order investigations and diagnostic tests, run clinics and prescribe drugs [13].

Although, among Nigerian health care professionals, controversy trails the use of oral drugs by physiotherapists but it appears global trend is favouring it. In the UK, Physiotherapists has now been listed among the supplementary prescribers [10]. The Medicines Act of 1968 was reviewed in UK to develop a framework to determine situations in which health professionals could undertake new roles in prescribing medicines. The Chartered Society of Physiotherapists (CSP) responded to this review and argued that physiotherapists should be given opportunity to prescribe and administer drugs in order to improve patient's care and maximize effective use of resources. UK Crown Report recommended that specialist physiotherapists be extended prescribing rights. Although, the right to prescribe medication was not about the profession but the utmost is to make patients have easy access to medications.

In the UK, both Dr June Crown and Beth Taylor are pharmacists and were resourced persons at a CSP conference on Prescribing Rights for Physiotherapists [2]. The opinion of pharmacists is very vital in given recognition and formulating policy for drug prescription by health professionals. It is therefore important and paramount to seek the opinion of pharmacists on prescription of drugs by physiotherapists. The main objective of this study was to determine the opinion of pharmacists on the need for legislation that will support enlistment of Nigerian physiotherapists as supplementary prescribers.

\section{Methodology}

\subsection{Subjects and Sampling Technique}

The population consisted of 150 practicing pharmacists who were willing to participate in the survey. The study took into consideration the willingness of the participants to answer the questionnaire and return it immediately. They were sample of convenience from 2 federal university teaching hospitals, 2 state hospitals, 1 private hospital, lacademic institution and 2 drug companies in south west Nigeria.

\subsection{Research Design}

This study was a cross sectional exploratory survey study.

\subsection{Instrumentation}

The instrument used in obtaining information for this study was a modification of a self administered questionnaire used by Onigbinde et al, [14]. The questions were kept as simple as possible with a Yes or No response format including free texts and checklist (of correct and incorrect answer). The questionnaire (as in appendix 1) was divided into 4 sections namely:

a. Demographics and Academic- related data: this constituted five questions ranging from bio-data to years of experience and where they work.

b. Section B had five questions, which addressed the attitude of pharmacists to the prescription of relevant medications by physiotherapists and the responsibility of the authority to provide information on relevant topical medications to physiotherapists.

c. Section C had 24 questions, 12 of which were of the 'Yes, No' option addressing their awareness about physiotherapists being supplementary prescribers in some countries and supporting the enlistment of physiotherapist in Nigeria. A pilot study was conducted prior to the actual data collection. A draft of the 
questionnaire was piloted in multistage phases. Firstly 5 pharmacists from Obafemi Awolowo University Teaching Hospital Complex (OAUTHC) who were not part of the main study were implored to complete the questionnaire. This was to determine whether the questions were clear and appropriate. On the basis of responses from these pharmacists, changes were made to the questions layout, content, wording and intent. The revised questionnaire was returned to these same pharmacists on about 3 occasions. Most of the participants actually sought for the simplification of the survey instrument by providing more 'yes/ no,' these changes were made again after discussions. The resultant questionnaire was sent to 5 academic pharmacists at Obafemi Awolowo University. The final questionnaire utilized for the study was the consensus copy agreed by all assessors.

\subsection{Procedure}

Ethical approval was obtained from the Research and Ethics Committee of the Institute of Public health Obafemi Awolowo University Ile-Ife, Osun state, Nigeria. Approval was also granted by the respective heads of departments of institutions, hospitals and pharmaceutical companies. One hundred and seventy (170) copies of the questionnaire were distributed but One hundred and fifty (150) copies were returned, representing a response rate of $88.2 \%$. Only 110 were analyzed, representing an overall response rate of $73.3 \%$, as 40 of the questionnaire was invalidated due to error in filling and inconsistencies. There was no restriction or time limit for the questionnaire to be completed.

\subsection{Data Analysis}

Descriptive statistics of frequency mean, standard deviation, percentages and Non parametric inferential statistics of Chi-square test were used to analyze the data obtained. Statistical package for social sciences software (SPSS Inc., Chicago, and U.S.A) was used.

\section{Results}

The mean age of participants in this study was $31.97 \pm$ 7.96 years. The result showed that 57 respondents $(51.8 \%)$ were males while 53 respondents $(48.2 \%)$ were females. Most respondents (86 [78.2\%]) opined that physiotherapists should source for relevant information from pharmacists while $44(46 \%)$ opined that they should source for information on relevant medications by self improvement or development. Other opinions are presented in Table 1.

Ninety four $(85.5 \%)$ reported that there was no existing policy regulating or guiding prescriptions by physiotherapists in Nigeria but $2(\%)$ were of the opinion that there was an existing policy and they reported that they follow this policy by honouring prescription from physiotherapists. On supporting an enactment, out of 96 respondents, 58 pharmacists $(60.4 \%)$ supported having an enabling law while
$34(39.6 \%)$ were against it (Table 2). The result of the MannWhitney $U$ test showed that the number of respondents who supported the formulation of policy to allow physiotherapists to prescribe was significantly higher than the number of respondents who opposed it $\left(\mathrm{X}^{2}=-5.99 ; \mathrm{P}<0.001\right)$.

Table 1. Opinion of respondents on sources where physiotherapists should sought for information to improve knowledge

\begin{tabular}{lll}
\hline Variables & Frequency & Percentage \\
\hline Self Development & 44 & 40 \\
MRTB & 18 & 16.4 \\
PSN & 27 & 24.5 \\
General Practitioners & 9 & 8.2 \\
Drug Companies & 28 & 25.5 \\
University Training & 32 & 29.1 \\
Pharmacists & 86 & 78.2 \\
\hline
\end{tabular}

MRTB $=$ Medical Rehabilitation Therapy Board, PSN= Pharmacists' society of Nigeria

Table 2. Opinion of Pharmacists on Policy and Enactment of Law.

\begin{tabular}{lccccc}
\hline Variables & & Frequency & Percentage & $\mathbf{X}^{\mathbf{2}}$ & $\mathbf{P}$ \\
\hline Existing & YES & 5 & 4.5 & - & - \\
policy & NO & 94 & 85.5 & - & - \\
Adhere & YES & 2 & 1.8 & - & - \\
policy & NO & 12 & 10.9 & - & - \\
Enactment & YES & 58 & 60.4 & & \\
& NO & 38 & 39.6 & -3.56 & 0.001 \\
\hline
\end{tabular}

Seventy respondents $(70 \%)$ supported the enlistment of Physiotherapists as Supplementary Prescribers while 30 respondents $(30 \%)$ didn't support the enlistment. Also, 60 respondents $(63.8 \%)$ are aware that physiotherapists are supplementary prescribers in some foreign countries (Table 3). The result of the Chi-square test showed that the number of respondents who supported the enlistment of Physiotherapists as Supplementary prescriber was significantly higher than those who opposed it $\left(\mathrm{X}^{2}=4.17 ; \mathrm{P}<\right.$ 0.04). Also, the number of respondents who are aware about physiotherapists being supplementary prescribers in some countries was significantly higher than number of those who were not aware $\left(\mathrm{X}^{2}=7.19 ; \mathrm{P}<0.007\right)$.

Seventy nine respondents $(71.8 \%)$ opined that physiotherapists should be allowed to prescribe NSAIDs while only 8 respondents $(7.3 \%)$ opined the prescription of anticoagulants by physiotherapists. Similarly, 73 (66.4\%) respondents opined physiotherapists should be allowed to prescribe analgesics while only 9 respondents $(8.2 \%)$ agreed on prescription of anti-depressants. Their opinion on other relevant drugs is presented in Table 4. Most Pharmacists $(71.9 \%)$ were unaware that cardiopulmonary physiotherapists can prescribe inhaler for patients requiring the use in some foreign countries while 57 respondents (51.8\%) were unaware of Pharmacophysiotherapy as a specialty (Table 5). 
Table 3. Awareness of Pharmacists about Physiotherapists being Supplementary Prescribers in some Countries

\begin{tabular}{llllll}
\hline Variables & & Frequency & Percentage & $\mathbf{X}^{\mathbf{2}}$ & $\mathbf{P}$ \\
\hline Supp & YES & 60 & 63.8 & - & - \\
Prescribers: & NO & 34 & 36.2 & -3.56 & 0.001 \\
Enlistment: & YES & 70 & 70 & - & - \\
& NO & 30 & 30 & -9.95 & 0.001 \\
\hline
\end{tabular}

Supp= Supplementary, PT= Physiotherapist

Table 4. Opinion on types of medications which physiotherapists should prescribe

\begin{tabular}{lll}
\hline Variables & Frequency & Percentage \\
\hline NSAIDs & 79 & 71.8 \\
Antibiotics & 24 & 21.8 \\
Analgesics & 73 & 66.4 \\
Vitamins & 33 & 30 \\
Anti-Coagulants & 8 & 7.3 \\
Corticosteroids & 12 & 10.9 \\
Anti-hypertensives & 24 & 21.8 \\
Anti-depressants & 9 & 8.2 \\
OTC & 46 & 41.8 \\
Anti-diabetes & 12 & 10.9 \\
\hline
\end{tabular}

NSAIDS $=$ Non Steroidal Anti-Inflammatory Drugs, OTC $=$ Over the Counter

Table 5. Familiarity with Prescription of Inhaler and awareness of pharmaco-physiotherapy as a specialty.

\begin{tabular}{llll}
\hline Variables & & Frequency & Percentage \\
\hline \multirow{2}{*}{ Prescribe Inhaler: } & YES & 29 & 26.4 \\
& NO & 79 & 71.8 \\
PharmacoPT: & YES & 51 & 46.4 \\
& NO & 57 & 51.8 \\
\hline
\end{tabular}

Table 6. Opinion on Undergraduate Pharmacology and Collaborative Study with Physiotherapists.

\begin{tabular}{llll}
\hline Variables & & Frequency & Percentage \\
\hline \multirow{2}{*}{ Pharmacology: } & YES & 62 & 56.4 \\
& NO & 47 & 42.7 \\
Collaborative Study: & YES & 14 & 12.7 \\
& NO & 94 & 85.5 \\
Drug Compoundment: & YES & 17 & 15.5 \\
& NO & 77 & 70 \\
Formal Presentation: & YES & 11 & 10 \\
& NO & 86 & 78.2 \\
\hline
\end{tabular}

The result showed that 62 respondents $(56.4 \%)$ are aware that physiotherapy students now have pharmacology education in their curriculum while 47 respondents $(42.7 \%)$ are not aware. Also, 14 respondents (12.7\%) have been involved in collaborative study with physiotherapists while 17 respondents (15.5\%) have compounded drugs for usage by physiotherapists and 11 respondents $(10.0 \%)$ have done a formal/informal seminar presentation at gatherings of physiotherapists (Table 6).

\section{Discussion}

The mean age of participants in this study was $31.97 \pm$ 7.96 years showing that majority are in the middle age while majority have Bachelor's degree in pharmacy and majority of them works in teaching hospitals, these implied that their responses should be adequate and factual for interpretation.
Most pharmacists reported that there was no existing policy regulating or guiding prescriptions by physiotherapists in Nigeria. A significant number of respondents supported the enlistment and enactment of laws that would permit physiotherapists to prescribe relevant medications while a significant number of respondents were aware about physiotherapists being supplementary prescribers in some countries. This lent credence to the report of Chartered Society of Physiotherapist on prescription rights for physiotherapists [2]. In United Kingdom, Crown Report recommended that specialist physiotherapists be extended prescribing rights [9]. It also legitimised current administration practice via patient specific directions (PSDs) and patient group direction (PGDs). Among common barriers to inter-professional healthcare team work is legal issues of scope of practice and liability [12].

Most pharmacists opined that physiotherapists should be allowed to prescribe NSAIDs and analgesics while very few agreed on prescription of anti-depressants. Grimmer et al reported evidence on the role of Physiotherapists in the use, recommendation and delivery of NSAIDs [5]. A moderate number agreed on prescription of muscle relaxants and this might be attributed to the high number of patients with upper motor neurone lesion with spasticity being managed by physiotherapists. Similarly, a moderate number agreed on prescription of OTC drugs. Lansbury and Sullivan observed that physiotherapists frequently advise their clients on the use of over-the -counter (OTC) medications and administer it in the course of treatment [15]. Kumar and Grimmer reported that legislation is required for physiotherapists to recommend drugs for patients, and also seek advice from medical practitioner or pharmacist [16]. It also supports the use of topical pharmacotherapy as an adjunct to electro- physical therapy and manual therapy

Most respondents opined that physiotherapists should source for relevant information on drugs from pharmacists. Although, Onigbinde et al reported that physiotherapists actively sought for information to update their knowledge from drug companies' seminars and journal articles [17]. This current finding also varied from that of Lansbury and Sullivan and Grimmer et al in Australia who observed that physiotherapists mostly source for information from Monthly Index of Medical Specialty (MIMS) and Medical practitioners [5,15].

Most Pharmacists are unaware that cardiopulmonary physiotherapists can prescribe inhaler for patients requiring the use in some foreign countries while slightly over $50 \%$ of respondents were not aware that there is a specialty known as pharmacotherapy. Onigbinde described pharmacotherapy as a concept where physiotherapy agent or modality is used in conjunction with drug therapy or is used to administer drug via mechanical and/or through electromotive force [17]. The linking of pharmacotherapy and physiotherapy is considered the most effective approach in recent days [18,19,20,21].

This study concluded that Pharmacists are of the opinion that physiotherapists should be enlisted as supplementary prescribers and that an enactment policy should be 
formulated to guide prescription of drugs.

\section{References}

[1] Chartered Society of Physiotherapy, 2013. Practice guidance for physiotherapist supplementary and/or independent prescribers in the safe use of medicines. (2nd Edition). Available through: <www.csp.org.uk/.../csp../csp_pd026_practice guidance_prescribers $>$.[Accessed 29 August, 2013].

[2] Chartered Society of Physiotherapy (2004). Prescribing Rights for Physiotherapists - an update August 2004 page 11. www.csp. Prescribing rightsforphysiotherapists.com. Accessed $13^{\text {th }}$ August 2013.

[3] Onigbinde A.T, Adedoyin R.A, Johnson O.E (2006): Effect of physical therapy interventions on pharmacokinetic variables: A preliminary review, Nigerian Journal of Medical Rehabilitation; Vol. 11.1

[4] Grimmer K, Kerr J, Hughes K, Trott P and Pitt M (1998): An overview of the Australian Physiotherapy Association accredited practice data collection 1995-1996. Australian Journal of Physiotherapy 44:61-63

[5] Grimmer K, Kumar S, and Gilbert A, et al (2002): NonSteroidal Anti-Inflammatory Drugs (NSAIDs). Physiotherapists' use, knowledge and attitudes: Australian Journal of Physiotherapy; Vol. 48' Pgs. 82-91

[6] Bissel Paul, Richard Cooper, Louise Guillaume, Claire Anderson, Anthony Avery, Allen Hutchinson, Veronica James, Joanne Lymn, Elizabeth Murphy, Julie Ratcliffe, Paul Ward, Ian Woosley (2008); An Evaluation of Supplementary Prescribing in Nursing and Pharmacy. Final report of Department of Health, The University of Shefield, eprint@whiterose.ac.uk. Accessed on the $19^{\text {th }}$ June 2014.

[7] American Speech-Language-Hearing Association, 2013). Inter-professional Education: Why is greater emphasis being placed on inter-professional education in health care? What impact will it have on the education of audiologists and speech-language pathologists? http://www.asha.org/academic/questions/InterprofessionalEducation/. Accessed on $14^{\text {th }}$ August 2013.

[8] ] BBC News Health, (2011). Supplementary Prescribing Rights in the UK. www.bbcnewshealth.com. Accessed on the $12^{\mathrm{th}}$ January 2014.

[9] Physioped (2012). Prescribing Rights in the UK. http://www.physio-pedia.com/Prescribing_Rights_in_the_UK. Accessed on 19th June 2014.

[10] MHRA (Medicines and Healthcare Products Regulatory Agency) (2002). In Prescribing Rights for Physiothe-rapists an update August 2004, page 11, ww.csp.org.uk.

[11] Crown Report (1999). Review of prescribing, supply and administration

of 354/http:/www.dh.gov.uk/prod_consum__ dh/groups /dh_digitalassets/@ dh/@en/documents/digital asset/dh_ 4077153.pdf $>$. Accessed 28 August, 2013.

[12] Grant RW, Finnocchio LJ and the California Primary Care Consortium Subcommittee on Interdisciplinary Collaboration. (1995). Common barriers to interprofessional healthcare team work. https://www.med.mun.ca/ Common-barriers-tointerprofessional-healthcare-te.aspx. Accessed on $16^{\text {th }}$ June 2014.

[13] NHS (2000) in Chartered Society of Physiotherapy (2004). Prescribing Rights for Physiotherapists - an update, August 2004, page 11, www.csp.org.uk

[14] Onigbinde, A.T., Bamitale, K.D.S., Olaogun, M.O.B., Makinde, O. O., Adetoogun, G.E., and Odeyemi, E. 2013. Opinion and knowledge of Nigerian physiotherapists on relevance and usefulness of pharmacology education on dosage of topical medications. InternationalJournal of Pharmacy and Pharmacology, 2 (1), pp. $55-63$.

[15] Lansbury and Sullivan (2002): Advising clients about prescription and medications; a survey of physiotherapeutic practice. Australian Journal of Physiotherapy. 88, No 1, Pgs. $18-24$

[16] Kumar S, Grimmer K (2005). Non-Steroidal AntiInflammatory Drugs (NSAIDs), and Physiotherapy Management of Musculoskeletal Conditions: a professional minefield? Centre for Allied Health Evidence, Australia. J. Clin. Risk Manag. 1(1): 69-76.

[17] Onigbinde AT, Olaogun MOB, Iroghue K (2012). An evaluation of the knowledge level of Nigerian physiotherapists on Topical pharmacology: HongKong Physiother. J. 30: $36-$ 42.

[18] Magos T. (2006): Interaction between pharmacotherapy and psychotherapy neurophysiologic basis. Neuropsychopharmacologia Hungarica Vol.8 No.2 Pgs.73-78. PMID: 17073215.mati@poni.hu

[19] Gladstone D.J Anna Czlonkowska et al (2009): Expert Opinion on Pharmacotherapy, Pharmacotherapy in Stroke Rehabilitation. Informa Healthcare, Vol.10, No.8, Pgs. 12491259 (doi: 10.1517/146560902941972)

[20] Olszewski J, Repetowski M, Kusmierczyk K (2007): Comparative assessment of results in cervical vertigo pharmacotherapy vs. Physiotherapy treatment Otolaryngologia Polska, Vol. 61, Issue 5, Pgs. 827-830.

[21] Zanfonte R.D, Munun M.C (2001): Phenol and Alcohol Blocks for the Treatment of Spasticity; Physical medicine Rehabilitation Clinic North America. Vol.12: Pgs.817-832 